\title{
Research on the Path of Student Management Reform in Chinese Universities Based on the Development of Students' Subject
}

\author{
LIU Wentong ${ }^{1, \text { a }}$, WANG Zhuo ${ }^{2}$ \\ ${ }^{1}$ Binzhou Polytechnic,College,Binxhou,Shandong,256624,China \\ aliuwentong@126.com
}

Keywords: student subject development, student management, reform

\begin{abstract}
The management of college students as a way to promote the quality of teaching in colleges and universities to promote teaching reform has always been the focus of the work of colleges and universities in China.In the actual management of college students, student management has shown the survival of the main state of decline, and this student lost the survival of the main reason is because the student's personal subject generated by the presupposition of the purpose of restrictions and uniform management model limits.On the current practice of most of the students in our country, there are still some disciplines, organizational space programming and other issues, and ultimately led to the loss of student subjects.This paper analyzes the causes of the loss of students 'development in the reform of college students' management, and puts forward some concrete suggestions on the path of college student management reform.
\end{abstract}

\section{Introduction}

With the transformation of the society, the reform of the internal management of colleges and universities has been continuously deepened, and this reform is to highlight the survival of the state of College Students' management of the loss of students.From the perspective of the practice of student management, there are still many problems in the management of college students in our country. The internal mechanism of student management is the inherent logic of the existence and development of students.In the reform of college student management, the loss of students' main body not only affects the improvement of teaching quality in Colleges and universities, but also relates to the practical development of colleges and Universities.In this paper, the students in the management of college students, the main body of the loss of the survival status of the analysis, the reasons for the loss of a deep analysis, and on the reform of college student management path.

\section{The analysis of the survival state of the students in the management of College students}

The limitation of students' individual subjectivity. The so-called individual subjectivity of students mainly refers to the basic attributes of the subject, which is also the key factor that makes the individual as the main body, which is mainly manifested in the people's autonomy in the thought and action. At present, the situation of College Students Management in our country will be too much emphasis on Students. The problem of teaching, plasticity and ignoring the individual subjectivity of students. In the "Cultural Revolution" period, the emphasis of college teaching is ideological reform, therefore, it is necessary for students to be reformed as a general thing. As a thing, the individual subjectivity is not taken seriously. After the reform and opening up, China's colleges and universities for student's management development, but there are still students blindly instill moral phenomenon in the process of Ideological and political education, just as knowledge is static experience to learn and accumulate, and no attention to the main body of knowledge behind. It is precisely because of this, the student's individual subjectivity is not paid attention to, coupled with the limited space for students to participate in the management of the organization, which will inevitably affect the student's individual subjectivity.

Student personality generated by the uniform management model restrictions. The so-called personality is a person's personal motivation, needs, interests, strengths and tendencies to understand 
a comprehensive reflection of personality is to promote people interested in things a key factor. The collective is embodied by the commonness of the individual, not only in the individual, but also in the individual. So we say that the real collective does not affect the generation of students' personality, but also allow personality to develop. In the student management work in colleges and universities, the use of "panoramic surveillance" supervision and management system, with a coercive means to constrain the behavior of students. In such a system, students not only to survive in the bureaucratic constraints, but also to accept the control of college student management. Obviously, the management model of college students in our country is mainly through the establishment of restraint to achieve a unified student management, which also to a certain extent, limits the individual choice of students, contrary to the meaning of modern education.

The generation of value rationality is limited by the rationality of instrumental hegemony. The so-called value rationality is the value of human existence in the sense of natural life and value of life. While the natural life advantage of the value of the carrier of life, making the value of life as a key to survival of a person. In terms of the historical evolution of the management of students in our country, most of them are mainly based on the rational management of students. It emphasizes the management of students as a political tool, so that students will naturally become political people. After the reform and opening up, most of our college students in the management of the work, for the cultivation of student skills and improve almost all of the students living in college, skills learning has become the only way to develop their own, the development of the country, and this approach makes students almost Was "brainwashing", that only technology can achieve the self-play and self-realization of the value, and ultimately make the students become the desire of the effort.

\section{The cause of college students in the management of the main reasons for the analysis of students}

The system of space regulation issues. In view of the needs of the new social period and the comprehensive development of the students, we analyze the practice of college students' management in terms of the management of college students in our country. According to the college students "bureaucratic panoramic surveillance" student management system, colleges and universities have established a bureaucratic management organizational structure. The purpose is to clear the division of powers and responsibilities, and strict implementation of the relevant registration services. Through a strict management system and formal provisions of the students to carry out panoramic surveillance, to this constraint method, forcing students to comply with the law, so as to achieve uniform school management results. However, under this system of restraint and security, students are likely to learn and live mechanically in order to cope with these tasks or instructions. At the same time, the student management of colleges and universities mainly focuses on compulsory and standardized management. From the historical evolution of student management, the students strictly manage, pay attention to the management of students, the system also use the "no" "not allowed" "prohibited" and other words. In the student management, teachers or managers are also more to the role of managers to communicate with students, seriously ignoring the objectivity of students to accept education differences.

The organization of space programming problems. In terms of the situation of student management in our country, the organizational space programming is mainly manifested in two aspects. On the one hand, from the macroscopic point of view, the organizational structure of student management in our country is mainly based on bureaucracy, and the units of the department or class are the organizational structure, and the rights distribution and affiliation of the vertical aspect are made clear the division. Every student in the university should be supervised and controlled by the management personnel, which makes the management staff become an important tool for the management of the students in the form of college students has become the transformation of the hands of the management of the object. Since the organizational structure of this bureaucracy is measured by the standard of order, that is, the ultimate goal of all management is to order the students. From the micro level, the class and professional as the most basic organizational unit, for the 
management of students usually to class as a unit, and this time, college student management is to focus on the class as a whole to achieve the goals and interests. Which may be standardized management of students, emphasizing the students in the class to have a consistent performance, which may lead to physical space constraints, resulting in the lack of communication between the different class students.

Cultural space control issues. There are two manifestations of spatial control of students' management culture in our country. On the one hand, the ideal of the entity, the so-called ideal entity is to talk about social forces as a student's life goals, each student should be in accordance with such social thought and live, colleges and universities through certain measures to make students sense of homogenization. After the reform and opening up, China's colleges and universities for the continuous reform and deepening of student management, but there are still instilling students of ideological and moral situation, this social force is a mandatory transformation of the students, Sex has become a cultural space control means. On the other hand, the homogenization of technology. As mentioned earlier, students' personal skills training has become an important part of student management. In the technical homogeneous social environment, people only possess the service and technology can satisfy the desire, so the student will become the slave of desire. College campus culture shows the loss of value rationality and the continuous expansion of instrumental rationality, obviously, which makes the skills of all students, the student's spiritual space will eventually be occupied by the interests.

\section{The analysis of the specific path of the reform of the student management in our country}

The management of college students is a kind of communicative practice, and the result of practice is the formation of students' main body. Therefore, in order to find the main body of College Students' management, we should start from the relationship between teachers and students, and put the essence of college student management into play. First of all, in order to promote teacher-student relationship, it must be the object of teacher-student relationship into the relationship between the subjects and the development of students as the main body, the formation of objective management intermediary often the relationship between subjective and objective, further demonstrated the person remind each other, form a "master" relationship with the teacher. The purpose is to promote the relationship between students and teachers, showing the relationship between students and teachers. As everyone knows, the student individual subjectivity is the function and characteristic of students as the theme expressed by the performance of this kind of person should be fully subjectivity of students in the school management activities, to actively participate in student affairs, further self-education, self-management and service.

In addition, the main body of the development of the reform of the management of students in Colleges and universities should continue to adjust the organizational structure. On the one hand, it is necessary to actively organize students to participate in the school management of students in the organization of space, so that students' self-education, self-management and self-service has been improved, the ultimate realization of learning. The development of the main body. At the same time, but also continue to expand the organization structure with the advice, guidance and service functions, and re combination according to the change of student management functions of colleges and universities. In addition, it should also set the corresponding student affairs management center, life service center, counseling center. And other institutions to provide professional services for the development of College Students. In order to realize the reform of student management in Colleges and universities in our country, we must pay attention to the reform of student management system. In the actual management of college students, we should fully reflect the core concept of students is the main body, which is also an important factor in determining student participation in school management activities. Including senior management decision-making, student affairs management and teaching and logistics management, etc. At the same time, should pay attention to reflect the level of students' participation in management of the right to do the exercise of the right to know, the right of suggestion, primary level supervision as the core, intermediate level emphasizes the exercise of the 
right action, right to consultation, but also pay attention to the exercise of decision-making power, the high level of voting.

\section{Summary}

In short, for our country's University Students' management reform, to achieve student's development objectives of the reform, we should analysis the factors of students lost state, and follow the principle of solving system of college student management work space discipline, organization of space program and cultural space of the full range of control problems, do to guide the students, serving the students management of students.

\section{References}

[1] Wang S H. Paying Attention to Students' Subject Development and Guiding Students' Self-Discipling[J]. Journal of Nanjing Institute of Mechanical Technology, 2011(4):18-27.

[2] Shi-Guangqian. Rights \& Interests and Orders: On Protecting Students' Rights in the Management System Reform of Higher Education[J]. Journal of Guangxi Youth Leaders College, 2015(13):208-217.

[3] Leblanc R J. The Limits to Reform: A Critical Discussion of the Saskatoon Public School Board's Assessment Controversy[J]. Organic \& Biomolecular Chemistry, 2011, 10(10):1992-2002.

[4] Lane H. Modeling the influence of school leaders on student achievement: How can school leaders make a difference?[J]. Educational Administration Quarterly: The Journal of Leadership for Effective \& Equitable Organizations, 2012, 48(4):699-732.

[5] Plourde L A. The influence of student teaching on preservice elementary teachers' science self-efficacy and outcome expectancy beliefs[J]. Journal of Instructional Psychology, 2002, 29(12):16-21

[6] Tural Dincer G, Akdeniz A R. Determining the Study Skills of Student Teachers.[J]. Online Submission, 2013.(16):115-119

[7] Jie X U, Wang Y, Ji Y U. The necessity of nutrition subject reform according to nutritive knowledge investigation among medical students[J]. Acta Academiae Medicinae Zunyi, 2012(37):33-37.

[8] Tanaka M. School Reform Through Micro-Management : A Case Study of the student : Centered School Shop Management in a School[J]. Journal of Jasea, 2011(43):188-197. 